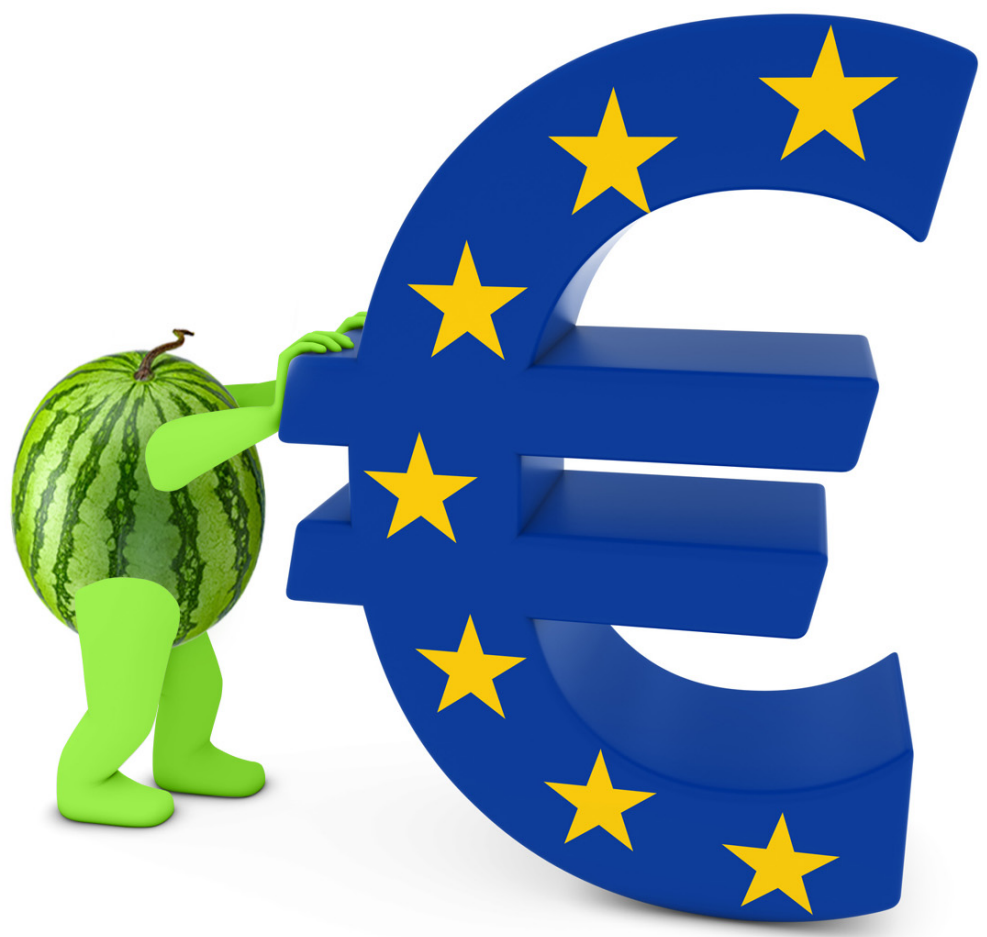

FINANCIAL ASPECTS OF RESEARCH AND DEVELOPMENT POLICY IN THE EUROPEAN UNION 


\title{
FINANCIAL ASPECTS OF RESEARCH AND DEVELOPMENT POLICY IN THE EUROPEAN UNION
}

\author{
Jerzy Baruk, PhD. Eng., Retired scientific-didactic employee at Maria Curie Skłodowska \\ University in Lublin, \\ Faculty of Economics, Institute of Management \\ jerzy.baruk@poczta.onet.pl \\ DOI: 10.2478/minib-2019-0041
}

\section{Summary}

In the article the author has attempted to realise the following goals:

1) identifying and critical assessment of the share of expenditure on research and development (R\&D) in the gross domestic product (GDP) borne by business entities concentrated in four sectors (enterprises, government, higher education and private non-profit institutions) and jointly in all sectors. This meter is treated as an indirect measure of the level of managerial activity in shaping the research and development policy,

2) checking the thesis that R\&D expenditure are changeable and differ in the particular Member States and does not give a clear positive picture of the systematic and dynamic growth of research and development activity in these countries.

The article was developed using the following research methods: critical-cognitive analysis of the literature; statistical and comparative analysis of the "Eurostat" empirical material; the projection.

The statistical and comparative analysis of the secondary empirical material "Eurostat" illustrating the share of expenditure on research and development in the gross domestic product was used to check the thesis. The results of the analysis confirm the rightness of the research thesis.

Keywords: research and development activity, innovation, development, knowledge, expenditure, management 



\section{Introduction}

The basic elements of any economy are economic operators with different objectives and scope and the resources needed to achieve them. They can operate in local, regional, national and global markets. The general objective of their functioning may be production, service or regulatory activity. They usually develop in conditions of: dynamic changes in their economic, political and social environment; strong competition on the market; rapid changes in technology and technology; difficult access to tangible and intangible resources - especially knowledge; dynamic changes in the expectations of current and potential customers; fast changing management methods, etc. As a result, they must have an efficient information/IT system that can identify as quickly as possible any changes in the internal and external (general and taskbased) environment (Griffin, 2007, pp. 75-89) with the objective: to record all signals (even weak ones) of changes in the environment; to react to these changes by adapting their structural, process, technical, technological, social, cultural and managerial solutions, the implementation of which will allow to maintain balance with the environment and even anticipate changes in the environment, as well as to create environments of mutual interaction between the enterprise and its customers (Li, Zhang and Wei, 2018, pp. 22).

Undoubtedly, the basic instrument of adjustment and anticipation changes are: product, process, organisational and marketing innovations (Baruk, 2018, pp. 88). The creation of such innovations should have a systemic character and result from a rational innovation policy conducted at the level of the country, region, every economic entity (Chen, Xia and Yang, 2018, pp. 39). Efficient creation of innovations is conditioned by having specific resources of scientific, market, technological and economic knowledge, because each innovation is created in the process of materialisation of the possessed resources of different categories of knowledge. Organisational knowledge is one of its most important resources, the basis for stable development, a source of maintaining the competitive character of the organisation (Wang and Chen, 2017, pp. 96). 
It is precisely the systemic search and transfer of new knowledge or the creative combination of existing ideas or technologies that has become a key condition for successful innovations (Xie, Hall, McCarthy, Skitmore and Shen, 2016, pp. 71). Such knowledge resources should be rationally managed through the implementation of a set of logical activities including the acquisition of knowledge, its storage, purification (updating), distribution, use and monitoring. Knowledge management models can facilitate the implementation of the knowledge management process (Baruk, 2009, pp. 32, 35-46). Conduct of managers in accordance with the indications of the models favours the shaping of a knowledge-based economy, characterised by systematically conducted research and development (R\&D) and innovative activity. Such a statement is particularly important in the light of the relatively low awareness of R\&D works, their understanding and the need for identification by management in Polish companies (Deloitte, 2016, pp. 10).

Research and development activity constitutes a source of knowledge for innovative processes and therefore should be an important element of research and development and innovation policy at the macro- and microeconomic level. This policy enables the creation of new knowledge, development of technologies increasing the ability of economic entities to create innovations and their practical use. Generally, R\&D works support organisations in systemic increase of knowledge resources (especially basic knowledge), knowledge of employees, enable disclosure and use of talents, acquiring external knowledge and improving innovative abilities. Thanks to rationally organised $R \& D$ works, business organisations acquire or develop important technologies internally or externally — through joint ventures, licences, strategic alliances and acquisitions (Salisu and Bakar, 2019, pp. 58).

The high rank of R\&D activity, treated as a source of materialised knowledge in the processes of creating and implementing innovations, requires creative involvement of managers in its systemic development. The scope of such involvement of managerial staff can be expressed indirectly by means of a measure in the form of a percentage share of expenditures on research and development in the gross domestic product. The analysis covered the development of this indicator in relation to: All 
sectors of activity; in the enterprise sector; in the government sector; in the higher education sector; in the sector of private non-profit institutions. The level of these measures, shaped in the years 2008; 2010; 2013; 2015 and 2017, was related to the EU, Poland and selected member states with relatively highest and lowest shares.

The aim of the publication is therefore an attempt to identify and critically assess the share of $R \& D$ expenditures in the gross domestic product (GDP) incurred by economic entities concentrated in four sectors (enterprises, government, higher education and private non-profit institutions) and in total in all sectors treated as an indirect measure of the degree of activity of management in shaping research and development policy.

The second objective of the study is an attempt to verify the thesis that R\&D expenditures are variable and differentiated in individual member states and do not give a clear positive picture ofthe systematic and dynamic growth of $R \& D$ activity in these countries.

The following research methods were used to prepare the publication: critical and cognitive analysis of literature; statistical and comparative analysis of secondary Eurostat empirical material; projection method.

\section{Principle of research and development}

Research and development activity includes systematically conducted creative works, carried out in order to increase knowledge resources, including knowledge about man, culture and society, as well as finding new opportunities to apply the acquired (discovered) knowledge (GUS, 2019, pp. 27). R\&D activity should be focused on new discoveries, based on original concepts or hypotheses and their interpretation. This activity is characterised by uncertainty about the final outcome or at least about the amount of time and resources needed to achieve it. The objective is to achieve results that can be freely transferred to practice or sold in the marketplace. These activities may be regarded as research and development if they meet the following criteria (OECD 2015, pp. 47): 
1) novelty - aiming at new discoveries,

2) creativity - based on original, unobvious concepts and hypotheses,

3) unpredictability - uncertainty about the final result and cost, including the time spent,

4) methodology - conducted in a planned manner (with a specific objective of the R\&D project and a source of financing),

5) transferability or reproducibility - resulting in results that can be reproduced.

The R\&D activity consists of:

1) fundamental research (clean and targeted),

2) applied research,

3) development work.

Basic research is experimental or theoretical work undertaken primarily to gain new knowledge of the underlying causes of phenomena and observable facts, without any focus on a specific application or use. This research is subdivided into:

- pure basic research leading to the advancement of knowledge, without economic or social benefit orientation and without active steps to apply the results of the research to solve practical problems or to transfer them to application sectors;

- oriented basic research aimed at creating a broad knowledge base that provides a basis for problem solving or for exploiting opportunities, both existing and foreseen in the future.

Applied research is original research work undertaken with the aim of acquiring new knowledge. They are mainly geared towards achieving specific practical objectives. This research involves taking into account existing knowledge and its 'broadening' to address specific problems. Applied research enables the operationalisation of ideas. Such knowledgebased solutions can be protected by intellectual property protection instruments, including trade secrets. Applied research may result in trial models of products, processes or methods. 
The functioning of an economic entity is illustrated by four logically consecutive sets of actions: research and development activity creating knowledge resources; innovative activity materialising the acquired knowledge; innovation-based operational activity consisting in manufacturing innovative products and providing innovative services; marketing activity / sales - placing innovative products or services on the market. Management of these sets of activities should be based on the assumptions of interrelated policies: $R \& D$, innovation and development, as well as systemically acquired scientific, technological, economic, market, commercial and customer knowledge.

Figure 1. Model of integration management of R\&D, innovative, operational and marketing activities in economic entities

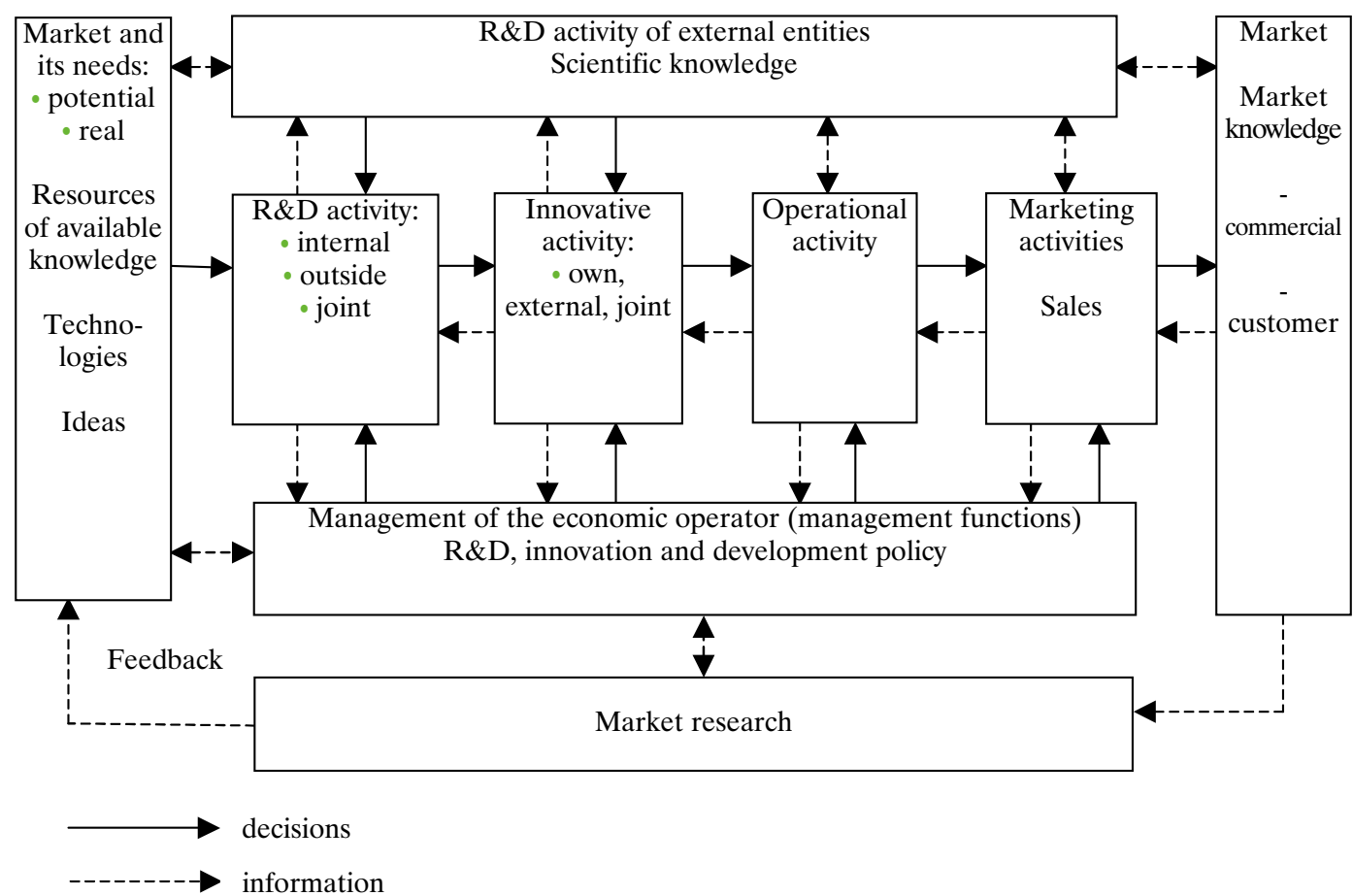

Source: Own elaboration. 


\section{Share of R\&D expenditure in GDP incurred in all sectors of activity}

R\&D activity is a cost-intensive activity, therefore it requires rational decisions on raising funds for this purpose, it also requires a coordinated policy on the scale of the whole economy, on the scale of regions and on the scale of individual economic entities. It is therefore justified to analyse how member states cope in shaping R\&D policy. A synthetic measure of such involvement may be the share of $R \& D$ expenditure in gross domestic product. Table 1 presents the development of this indicator for the EU, Poland and selected Member States in selected years.

Table 1. Share of R\&D expenditure in GDP incurred in all sectors of activity (in \%)

\begin{tabular}{l|c|c|c|c|c}
\hline \multirow{2}{*}{ Specification } & \multicolumn{5}{c}{ Percentage share in years } \\
\cline { 2 - 6 } & $\mathbf{2 0 0 8}$ & $\mathbf{2 0 1 0}$ & $\mathbf{2 0 1 3}$ & $\mathbf{2 0 1 5}$ & $\mathbf{2 0 1 7}$ \\
\hline European Union (UE-28) & $\mathbf{1 . 8 3}$ & $\mathbf{1 . 9 2}$ & $\mathbf{2 . 0 2}$ & $\mathbf{2 . 0 4}$ & $\mathbf{2 . 0 7}$ \\
Poland & $\mathbf{0 . 6 0}$ & $\mathbf{0 . 7 2}$ & $\mathbf{0 . 8 7}$ & $\mathbf{1 . 0 0}$ & $\mathbf{1 . 0 3}$ \\
Countries with the highest shares: & & & & & \\
Finland & 3.55 & 3.73 & 3.29 & 2.90 & 2.76 \\
Sweden & 3.49 & 3.21 & 3.30 & 3.26 & 3.33 \\
Denmark & 2.77 & 2.92 & 2.97 & 3.06 & 3.06 \\
Germany & 2.60 & 2.71 & 2.82 & 2.91 & 3.02 \\
France & 2.06 & 2.18 & 2.24 & 2.27 & - \\
Countries with the lowest shares: & & & & & \\
Bulgaria & 0.45 & 0.56 & 0.64 & 0.96 & 0.75 \\
Cyprus & 0.39 & 0.45 & 0.48 & 0.48 & 0.56 \\
Romania & 0.55 & 0.46 & 0.39 & 0.49 & 0.50 \\
Latvia & 0.58 & 0.61 & 0.61 & 0.63 & 0.51 \\
USA & 2.77 & 2.74 & 2.73 & 2.76 & - \\
Japan & 3.34 & 3.14 & 3.32 & 3.28 & - \\
South Korea & 3.12 & 3.47 & 4.15 & 4.22 & - \\
\hline
\end{tabular}

Source: Own elaboration based on: https://ec.eurostat/tgm/printTable. (accessed on 31.12.2018). 
In the years under consideration, the share of $R \& D$ expenditure in GDP was diversified in terms of value and upward trends. At the EU level, in 2008 and 2010 this share did not exceed 2\%, while in the three remaining years it exceeded the $2 \%$ limit with a slight upward trend. The Member States contributed to such a situation by clearly differentiated in terms of the level of GDP allocated to R\&D. The following countries stood out positively Finland, Sweden, Denmark, Germany and to a lesser extent France. In these countries, the level of the analysed measure was higher than the average value for the EU in particular years. Sweden stood out in particular, where the share exceeded $3 \%$, but without a clear upward trend. In Finland, in the initial three years it exceeded 3\%, but in the following two years it had a decreasing tendency. The opposite was the case in Denmark, where in 2008, 2010 and 2013 the indicator remained at a level below $3 \%$, but with a slight upward trend, to exceed the $3 \%$ limit in subsequent years. The indicator reached a slightly lower level in Germany, showing a slight upward trend, and in 2017 it went beyond $3 \%$.

The opposite group were countries with relatively small shares of R\&D expenditure in GDP. This is mainly the case for Cyprus, Romania, Latvia and Bulgaria. In these countries, the level of the analysed measure did not exceed $1 \%$ and had irregular growth trends. In particular years, these shares significantly differed from the average values in the EU.

In Poland, R\&D expenditures were at a much lower level than the EU average. A positive phenomenon was the small but growing character of the considered measure from $0.6 \%$ in 2008 (less than 1.23 pps. compared to the average result in the EU) to $1.03 \%$ in 2017 (less than 1.04pps. compared to the EU average). The shares of R\&D expenditure in GDP place Poland in the group of countries that have to catch up with the European leaders.

In the context of the analysis, the question arises: what is the position of the EU and individual Member States against the background of the level of the considered measure characterising the leading countries in this respect, such as the USA, Japan, or South Korea? It turns out that the average results for the EU were lower than 
those achieved in the USA in 2008 - by $0.94 \mathrm{pps}$. in 2010 . - by $0.82 \mathrm{pps}$. in 2013 . - by $0.71 \mathrm{pps}$, in 2015 - by $0.72 \mathrm{pps}$., no data for the USA for 2017. The presented figures show that the technology gap between the EU and the US, Japan and South Korea persists, despite the optimistic assumptions of the Europe 2020 strategy to improve the R\&D environment, including by devoting $3 \%$ of EU GDP to R\&D investment (Strategy 2015, pp. 1). Among the Member States, only Sweden met this condition in the analysed years. While Finland - in 2008, 2010 and 2013. Denmark reached the target level in 2015 and 2017, while Germany only in 2017.

Even greater differences in the share of R\&D expenditure in GDP emerged between the EU and Japan and South Korea. In Japan, R\&D expenditure accounted for more than $3 \%$ of GDP. The situation was even more favourable in South Korea, where in 2013 and 2015 the share exceeded 4\%.

\section{$R \& D$ expenditure as a share of GDP in the enterprise sector}

The enterprise sector includes (OECD 2015, pp. 34):

1) all resident enterprises, including not only incorporated enterprises, regardless of the place of residence or place of residence of their shareholders or associates. Included here are both private enterprises (listed and traded enterprises or not) and public sector enterprises (i.e. enterprises controlled by the government sector),

2) unincorporated branches of non-resident enterprises, considered as residents and part of this sector because they are engaged in production in the economic territory concerned in the long term,

3) all resident non-profit institutions that are producers of goods or services in the market or provide services to businesses.

In the context of the conducted analysis, the question is justified: what was the share of R\&D expenditure in GDP incurred in the sector of 
enterprises? As it can be seen from Table 2, the level of this indicator assumed different values in particular member states.

On average in the EU, this expenditure reached a level exceeding $1 \%$ of GDP and showed an upward trend from $1.16 \%$ in 2008 to $1.36 \%$ in 2017. However, the member states showed significant differences in the level of this measure in relation to other countries, as well as in individual years. The sectors of enterprises in Sweden and Finland stood out positively. In these countries, the measure significantly exceeded the EU average, reaching over 2\% except in Finland, where it fell to $1.93 \%$ in 2015. Positive trends were noted in Austrian and German companies, where the analyzed shares were characterized by a constant, albeit small, upward trend. For Austria, from 1.78\% in 2008 to 2.22\% in 2017. For Germany, from $1.8 \%$ in 2008 to $2.09 \%$ in 2017 . At a higher level than the EU average, this indicator was also higher in Denmark, but it was relatively stable.

Some EU Member States were characterized by much lower levels of the considered measure. This statement applies especially to Cyprus, Romania, Latvia, Lithuania and Slovakia. In these countries, R\&D expenditures incurred by the enterprise sector were at a relatively low and diversified level. The worst situation was observed among Cypriot enterprises, where in 2008 the considered measure reached the level of $0.09 \%$, and in 2017 it increased to mere $0.2 \%$. A positive phenomenon in the sectors of Lithuanian and Slovak enterprises were small but systematic increases of the surveyed measure in the analysed years. In the case of Lithuania - from 0.19 in 2008 to $0.31 \%$ in 2017 and in the case of Slovakia - from $0.2 \%$ in 2008 to $0.48 \%$ in 2017 .

The share of R\&D expenditure in the GDP of the Polish enterprises sector was significantly smaller in comparison with the average results in the EU. In Poland in 2008 this indicator was lower by $0.97 \mathrm{pps}$, in 2010 - by 1 percentage point, in 2013 - by $0.9 \mathrm{pps}$, in 2015 - by 0.84 pps. and in 2017 by 0.67 pps. Despite a relatively low share of R\&D expenditure in GDP incurred by the enterprise sector in Poland, positive tendencies can be observed, manifested by a decreasing gap in relation to average results in the EU and a slight increase in the measure in subsequent years, with the exception of 
2010. However, the absolute values of this indicator place Polish enterprises in the group of countries with a relatively low level of $R \& D$ financing.

Table 2. R\&D expenditure as a share of GDP in the enterprise sector (in \%)

\begin{tabular}{l|c|c|c|c|c}
\hline \multirow{2}{*}{ Specification } & \multicolumn{5}{c}{ Percentage share in years } \\
\cline { 2 - 6 } & $\mathbf{2 0 0 8}$ & $\mathbf{2 0 1 0}$ & $\mathbf{2 0 1 3}$ & $\mathbf{2 0 1 5}$ & $\mathbf{2 0 1 7}$ \\
\hline European Union (UE-28) & $\mathbf{1 . 1 6}$ & $\mathbf{1 . 1 9}$ & $\mathbf{1 . 2 8}$ & $\mathbf{1 . 3 1}$ & $\mathbf{1 . 3 6}$ \\
Poland & $\mathbf{0 . 1 9}$ & $\mathbf{0 . 1 9}$ & $\mathbf{0 . 3 8}$ & $\mathbf{0 . 4 7}$ & $\mathbf{0 . 6 7}$ \\
Counties with the highest shares: & & & & & \\
Sweden & 2.59 & 2.21 & 2.28 & 2.27 & 2.35 \\
Finland & 2.63 & 2.59 & 2.26 & 1.93 & 2.80 \\
Germany & 1.80 & 1.82 & 1.90 & 2.00 & 2.09 \\
Denmark & 1.94 & 1.96 & 1.88 & 1.94 & 1.97 \\
Austria & 1.78 & 1.87 & 2.09 & 2.18 & 2.22 \\
Countries with the lowest shares: & & & & & \\
Cyprus & 0.09 & 0.08 & 0.09 & 0.11 & 0.20 \\
Romania & 0.17 & 0.18 & 0.12 & 0.21 & 0.29 \\
Latvia & 0.15 & 0.23 & 0.17 & 0.15 & 0.14 \\
Lithuania & 0.19 & 0.23 & 0.24 & 0.29 & 0.31 \\
Slovakia & 0.20 & 0.26 & 0.38 & 0.33 & 0.48 \\
USA & 1.98 & 1.86 & 1.92 & 1.97 & - \\
Japan & 2.62 & 2.40 & 2.52 & 2.57 & - \\
South Korea & 2.35 & 2.59 & 3.26 & 3.27 & - \\
\hline
\end{tabular}

Source: Own elaboration based on: https://ec.eurostat/tgm/printTable. (accessed on 31.12.2018).

Also in this section of the analysis, the average results for the EU in comparison to those of the USA, especially Japan and South Korea, are not satisfactory. In the USA, this indicator was similar to $2 \%$ in individual years and exceeded the average values in the EU by 0.79 pps. in 2008 , it was by 0.67 pps. in 2010 , it was by 0.64 ppm. - in 2013 , by 0.66 pp. - in 2015. In Japan and South Korea, the average was $2.53 \%$ and $2.87 \%$ respectively. 


\section{Share of R\&D expenditure in GDP of the government sector}

One of the important entities creating research and development policy is the governments of individual countries and their agendas. The measure of such involvement may be the share of $R \& D$ expenditures in the GDP incurred by the government sector, which it consists of (OECD 2015, pp. 35):

1) all units of central/federal, regional/state and local/communal authorities, including social security institutions, except for those units that correspond to the description of higher education institutions,

2) other general government: R\&D performing or financing agencies and all non-market nonprofit institutions which are controlled by general government units and which do not themselves belong to the higher education sector.

The level of this measure is shown in Table 3.

At EU level, the average share of R\&D expenditure in Member State governments' GDP was around $0.25 \%$ and stable. In the cross-section of the Member States, the values of the analysed measure differed from the average results for the EU. They also differed between individual countries. In countries such as Germany, the Czech Republic, Luxembourg, Slovenia and Finland, the share of government R\&D expenditure in GDP was slightly higher than the average results in the EU, but it did not clearly increase in subsequent years. The most distinctive country was Germany, where the government sector spent about $0.4 \%$ of GDP on R\&D in particular years.

At the opposite end of the scale they were: Malta, Ireland, Cyprus, Denmark and Portugal. In these countries, the levels of the analysed measure were significantly lower than the average values for the EU. These results indicate a vestigial involvement of the government sector in financing research and development. In Malta, for example, the share 
of the government sector in R\&D funding in 2008 and 2010 was $0.02 \%$ of GDP. The situation was even worse in 2017. In Portugal, the value of the analysed measure decreased from $0.11 \%$ in 2008 to $0.07 \%$ in 2017 .

Table 3. Share of R\&D expenditure in GDP

of the government sector (in \%)

\begin{tabular}{l|c|c|c|c|c}
\hline \multirow{2}{*}{ Specification } & \multicolumn{5}{c}{ Percentage share in years } \\
\cline { 2 - 6 } & $\mathbf{2 0 0 8}$ & $\mathbf{2 0 1 0}$ & $\mathbf{2 0 1 3}$ & $\mathbf{2 0 1 5}$ & $\mathbf{2 0 1 7}$ \\
\hline European Union (UE-28) & $\mathbf{0 . 2 4}$ & $\mathbf{0 . 2 5}$ & $\mathbf{0 . 2 5}$ & $\mathbf{0 . 2 4}$ & $\mathbf{0 . 2 3}$ \\
Poland & $\mathbf{0 . 2 1}$ & $\mathbf{0 . 2 6}$ & $\mathbf{0 . 2 3}$ & $\mathbf{0 . 2 4}$ & $\mathbf{0 . 0 2}$ \\
Counties with the highest shares: & & & & & \\
Germany & 0.36 & 0.40 & 0.42 & 0.41 & 0.41 \\
Czech Republic & 0.29 & 0.29 & 0.35 & 0.39 & 0.31 \\
Luxemburg & 0.26 & 0.32 & 0.38 & 0.38 & 0.33 \\
Slovenia & 0.36 & 0.37 & 0.34 & 0.30 & 0.26 \\
Finland & 0.29 & 0.34 & 0.29 & 0.24 & 0.24 \\
Counties with the lowest shares: & & & & & \\
Malta & 0.02 & 0.02 & 0.07 & 0.12 & 0.01 \\
Ireland & 0.09 & 0.08 & 0.07 & 0.05 & 0.05 \\
Cyprus & 0.09 & 0.09 & 0.07 & 0.06 & 0.06 \\
Denmark & 0.07 & 0.06 & 0.07 & 0.07 & 0.07 \\
Portugal & 0.11 & 0.11 & 0.09 & 0.08 & 0.07 \\
South Korea & 0.38 & 0.44 & 0.45 & 0.50 & - \\
USA & 0.31 & 0.35 & 0.31 & 0.31 & - \\
Russia & 0.29 & 0.32 & 0.31 & 0.34 & - \\
Hong Kong & 0.26 & 0.31 & 0.32 & 0.33 & - \\
\hline
\end{tabular}

Source: Own elaboration based on: https://ec.eurostat/tgm/printTable. (accessed on 31.12.2018).

In Poland, the financing of research and development by the government sector measured as a percentage share of R\&D expenditure in GDP was similar to the average results in the EU and remained at a level slightly exceeding $0.2 \%$, except in 2017, when the value of this indicator fell to only $0.02 \%$. This puts Poland in second place since the end of the Member States before Malta.

For comparison, in several countries around the world, the value of the surveyed indicator was higher than the EU average. These countries 
include: South Korea, USA, Russia and Hong Kong, where the level of government spending on R\&D was slightly above $0.3 \%$ of GDP, while in South Korea it oscillated between $0.38 \%$ in 2008 and $0.5 \%$ in 2015 .

The gap in the level of the analysed indicator between the EU and the USA was: The gap in the level of the analysed indicator between the EU and the USA was: 0.07pps. in 2008, 0.1pps. in 2010, 0.06 pps. in 2013, and $0.07 \mathrm{pps}$. in 2015 .

\section{R\&D expenditure as a share of GDP in the higher education sector}

One sector that should be strongly involved in $R \& D$ is the higher education sector to which belong: (OECD 2015, pp. 36):

1) all universities, technical universities and other institutions providing formal higher education programmes, regardless of their source of funding and legal status,

2. all research institutes, centres, testing centres, stations and clinics which conduct $R \& D$ activities under the direct control or guidance of higher education institutions.

This commitment can be manifested in the funding of research and development. The question arises: what was the share of $R \& D$ expenditure in the GDP of the higher education sector in the EU and in selected member states in the analysed period? The values of this indicator are presented in Table 4.

It turns out that on average in the EU, R\&D expenditure incurred by the higher education sector amounted to over $0.4 \%$ of GDP and was rather stable in particular years. On the other hand, the shares in each Member State differed significantly, which allowed to distinguish the group of countries with the highest shares, significantly exceeding the average results in the EU, such as Denmark, Sweden, Finland and Austria, as well as the groups of countries with the lowest shares, clearly below the EU average, such as Bulgaria, Romania, Luxembourg and Hungary. In the first 
group of countries, Denmark stood out in particular, where in 2013, 2015 and 2017 expenditures of the higher education sector on R\&D exceeded $1 \%$ of GDP. None of the other member states had such a level of funding per year.

Table 4. R\&D expenditure as a share of GDP

in the higher education sector (in \%)

\begin{tabular}{l|c|c|c|c|c}
\hline \multirow{2}{*}{ Specification } & \multicolumn{5}{c}{ Percentage share in years } \\
\cline { 2 - 6 } & $\mathbf{2 0 0 8}$ & $\mathbf{2 0 1 0}$ & $\mathbf{2 0 1 3}$ & $\mathbf{2 0 1 5}$ & $\mathbf{2 0 1 7}$ \\
\hline European Union (UE-28) & $\mathbf{0 . 4 2}$ & $\mathbf{0 . 4 7}$ & $\mathbf{0 . 4 7}$ & $\mathbf{0 . 4 7}$ & $\mathbf{0 . 4 6}$ \\
Poland & $\mathbf{0 . 2 0}$ & $\mathbf{0 . 2 7}$ & $\mathbf{0 . 2 5}$ & $\mathbf{0 . 2 9}$ & $\mathbf{0 . 3 4}$ \\
Counties with the highest shares: & & & & & \\
Denmark & 0.75 & 0.88 & 1.01 & 1.04 & 1.01 \\
Sweden & 0.74 & 0.85 & 0.90 & 0.87 & 0.86 \\
Finland & 0.61 & 0.76 & 0.71 & 0.71 & 0.70 \\
Austria & 0.64 & 0.70 & 0.72 & 0.72 & 0.70 \\
Counties with the lowest shares: & & & & & \\
Bulgaria & 0.04 & 0.07 & 0.06 & 0.05 & 0.04 \\
Romania & 0.16 & 0.11 & 0.08 & 0.09 & 0.05 \\
Luxemburg & 0.10 & 0.19 & 0.24 & 0.24 & 0.25 \\
Hungary & 0.22 & 0.23 & 0.20 & 0.17 & 0.18 \\
USA & 0.37 & 0.40 & 0.38 & 0.37 & - \\
Japan & 0.39 & 0.40 & 0.45 & 0.40 & - \\
South Korea & 0.35 & 0.38 & 0.38 & 0.38 & - \\
\hline
\end{tabular}

Source: Own elaboration based on: https://ec.eurostat/tgm/printTable. (accessed on 31.12.2018).

Among the countries of the second group, the lowest values of the analysed measure were characteristic for Bulgaria. They stood at $0.04 \%$ in 2008 and 2017 and $0.07 \%$ in 2010 . Slightly better results were recorded in this respect by Romania, especially in 2017.

In Poland, the higher education sector spent between $0.2 \%$ of GDP in 2008 and $0.34 \%$ of GDP in 2017 on R\&D. These results were lower than the EU average by 0.22 pps. in 2008 , by 0.2 pps. in 2010 , by 0.22 pps. in 2013 , by 0.18 pps. in 2015 , and by 0.12 pps. in 2017 . A positive trend is the fact that the level of the analysed measure gradually, albeit slightly, increases in the consecutive years of the analysis. 
Comparing the average level of the analysed indicator in the EU with the results characteristic for the leading countries, it should be noted that in the EU, in comparison with the USA, the share of R\&D expenditure in GDP incurred by the higher education sector was higher by 0.05 per cent in 2008 , by 0.07 per cent in 2010 , by 0.09 per cent in 2013 and by 0.1 per cent in 2015. In the analysed cross-section of the analysis, the average values of the analysed indicator in the EU also exceeded the same parameter characterising Japan and South Korea, which is a favourable phenomenon.

\section{Share of R\&D expenditure in GDP of private non-profit institutions}

Non-profit institutions are legal persons or social entities set up for the purpose of manufacturing goods and services, but their status does not permit them to be a source of income, profit or other financial benefit to the entities setting them up, controlling or financing them. These institutions may carry out market or non-market production. This sector is composed of (OECD 2015, pp. 110):

1) all non-profit institutions serving households, except those in the higher education sector;

2. households and individuals engaged in, or not engaged in, market activities.

Examples of units belonging to this sector are independent professional and scientific associations and charitable organisations which are not controlled by units belonging to the government sector or the business sector.

The share of R\&D expenditure in the GDP of such organisations is shown in Table 5.

On average in the EU, it stood at $0.02 \%$ between 2008 and 2015. Its value varied across Member States. The highest values were recorded in 
Cyprus from 0.04 in 2008 to 0.07 in 2015 and 2017. In Italy, the share of R\&D expenditure in GDP in the private non-profit sector remained at $0.04 \%$, before falling to $0.02 \%$ in 2017 . This indicator was slightly lower in the UK and France.

Table 5. R\&D expenditure as a share of GDP

of private non-profit institutions (in \%)

\begin{tabular}{l|c|c|c|c|c}
\hline \multirow{2}{*}{ Specification } & \multicolumn{5}{c}{ Percentage share in years } \\
\cline { 2 - 6 } & $\mathbf{2 0 0 8}$ & $\mathbf{2 0 1 0}$ & $\mathbf{2 0 1 3}$ & $\mathbf{2 0 1 5}$ & $\mathbf{2 0 1 7}$ \\
\hline European Union (UE-28) & $\mathbf{0 . 0 2}$ & $\mathbf{0 . 0 2}$ & $\mathbf{0 . 0 2}$ & $\mathbf{0 . 0 2}$ & - \\
Poland & $\mathbf{0}$ & $\mathbf{0}$ & $\mathbf{0}$ & $\mathbf{0}$ & $\mathbf{0}$ \\
Counties with the highest shares: & & & & & \\
Cyprus & 0.04 & 0.06 & 0.06 & 0.07 & 0.07 \\
Italy & 0.04 & 0.04 & 0.04 & 0.04 & 0.02 \\
Great Britain & 0.04 & 0.04 & 0.03 & 0.03 & 0.04 \\
Francja & 0.03 & 0.03 & 0.03 & 0.03 & - \\
Counties with the lowest shares: & & & & & \\
Spain & 0 & 0 & 0 & 0 & 0 \\
Romania & 0 & 0 & 0 & 0 & 0 \\
Slovakia & 0 & 0 & 0 & 0 & 0 \\
Slovenia & 0 & 0 & 0 & 0 & 0.01 \\
USA & 0.11 & 0.12 & 0.11 & 0.11 & - \\
Japan & 0.05 & 0.05 & 0.04 & 0.04 & - \\
South Korea & 0.04 & 0.06 & 0.06 & 0.07 & - \\
\hline
\end{tabular}

Source: Own elaboration based on: https://ec.eurostat/tgm/printTable. (accessed on 31.12.2018).

In the group of member states there were also those in which private non-profit institutions were completely passive in financing research and development. Such countries were: Spain, Romania, Slovakia and Poland. In Slovenia, however, only in 2017 these organisations allocated $0.01 \%$ of GDP to R\&D.

For comparison, in the USA this indicator remained at the level of $0.11 \%$ and in 2010 at the level of $0.12 \%$. In comparison with the average values in the EU, it was higher by 0.09 pps. in 2008 , by 0.1 pps. in 2010 , by 0.09 pps. in 2013 and 2015 . 
In Japan, private non-commercial institutions spent $0.05 \%$ of GDP on R\&D in 2008 and 2010 and $0.04 \%$ in 2013 and 2015. While in Japan these shares slightly decreased, South Korea recorded a slight increase from $0.04 \%$ in 2008 to $0.06 \%$ in 2010 and 2013 and to $0.07 \%$ in 2015 .

\section{Summary}

The publication attempts to achieve two objectives which are as follows:

1) analysing and critically evaluating the share of $R \& D$ expenditure in the gross domestic product (GDP) incurred by economic entities concentrated in four sectors (enterprises, government, higher education and private non-profit institutions) and jointly in all sectors treated as an indirect measure of the degree of activity of management in shaping R\&D policy,

2) verification of the thesis that $R \& D$ expenditure in individual Member States is variable over time and differentiated in terms of share in GDP and does not give a clear positive picture of the dynamic growth of $R \& D$ activity in these countries.

Critical and cognitive analysis of the available empirical material confirmed the above thesis. Numerical values of the adopted measure characteristic for the EU, as well as for selected Member States with the highest and lowest shares of R\&D expenditures in GDP, allow to rank the sectors under consideration from the highest activity to the lowest. The first place was taken by the enterprise sector, followed by the higher education sector before the government sector and the private non-profit sector. In the enterprise sector, the average values of the indicator in the EU were increasing, which is a positive phenomenon, suggesting a certain rationality of $R \& D$ policy. A similar situation took place in Germany and Austria - among the countries with the highest shareholding and Lithuania. However, in many member states these shares varied irregularly in terms of value in particular years, e.g. from $2.8 \%$ in Germany to $0.14 \%$ in Latvia (in 2017); from $2.63 \%$ in Finland to $0.09 \%$ in Cyprus (in 2008). 
In terms of the share of R\&D expenditure in GDP, the sector of enterprises in Poland was characterized by a small, although systematic increase in the consecutive years of analysis (which is a positive phenomenon), but these shares were much lower (well below 1\%) than the average results for the EU, which places Poland in the group of marauding countries, which clearly differ from the average level in the EU, especially from the leading countries.

The second place in terms of the level of the analysed indicator was taken by the higher education sector, where the share of $R \& D$ expenditure in GDP (average results for the EU) remained at the level below $0.5 \%$ and was relatively stable in particular years. However, across member states, the analysed shares differed significantly from the EU average both upwards and downwards. For example, in 2008 in Denmark it was $0.75 \%$, in Bulgaria only $0.04 \%$; in 2017 in Denmark it was $1.01 \%$ and in Bulgaria 0.04\%, in Romania it was $0.05 \%$.

It should be emphasized that in particular years the values of this measure changed irregularly and did not have unambiguously growing tendencies.

In Poland, the higher education sector was characterised by a much smaller share of R\&D expenditure in GDP compared to the average results in the EU. However, a positive phenomenon was their growth from $0.2 \%$ in 2008 to $0.34 \%$ in 2017.

The government sector was ranked next in terms of the share of R\&D expenditure in GDP. On average, its share in the EU did not exceed $0.25 \%$ and since 2013 it has been on a declining trend.

In the cross-section of selected member states, these shares were different in terms of value and in particular years. For example, in Germany this indicator remained at a level slightly above $0.4 \%$, but in Malta it did not exceed $0.1 \%$ with the exception of 2015 .

The lowest and irregular values of the surveyed indicator were recorded in the sector of private non-profit institutions. On average in the EU, they remained at the level of $0.02 \%$, while in distinguishing countries they reached from $0.03 \%$ to $0.07 \%$. In countries such as Spain, Romania and Slovakia private non-profit institutions did not spend any funds on R\&D. 
The levels of the surveyed measure indicate a gap between the EU and the USA, Japan and South Korea. This gap occurs both in the crosssection of all sectors of activity (Table 1) as well as in particular sectors, i.e. enterprises, government and private non-profit institutions. The exception is the higher education sector, where the share of R\&D expenditure in GDP on average in the EU was higher than in the USA, Japan and South Korea.

The variable and time-varying level of the surveyed measure allows to assume that in the EU member states no effective R\&D policy instruments have been developed aimed at rational creation of knowledge that would be materialised in innovations, especially radical (strategic) ones that would systematically satisfy the current and future needs of customers. This statement applies especially to countries characterised by relatively low shares of R\&D expenditure in GDP, including Poland. In these countries, development policies are more focused on the implementation of operational sentences than on the creation of the future. The reasons for such a situation may be: external, internal, economic, social, cultural, organisational, technical, mental barriers, etc. Probably many managers, fearing the risk associated with R\&D activity, avoid investing in systemic development of this activity treated as a source of knowledge necessary to create innovations, especially radical ones. It can be assumed that one of such barriers is the lack of ability to shape research and development policy both at the national and regional level, as well as at the level of the economic entity and its coordination at all levels of management.

The relatively low level of $R \& D$ work is caused by management errors, manifested by poor knowledge of modern management methods (including knowledge and innovation management), dominance in decision-making processes of operational activity, limited interest in strategic management, underestimation of the influence of organisational culture (innovative) on the increase of interest of employees and individual customers in creating knowledge and its use in solving emerging problems. Knowledge management should be treated equally to the management of human and material resources of an organization, not only as a discreet management function, but also as a 
unique skill, because it is a significant catalyst for creating innovation and the value it contains for the organization and its customers.

Integrated knowledge and innovation management must serve to streamline and support the creation and implementation of innovation and the development of innovation processes as a core competence of economic operators (Gloet and Samson, 2019, pp. 20). A significant facilitation for managers of $R \& D$ and innovation activity may be to follow selected innovation models, as each of them is based on a close relationship between $R \& D$ and innovation activity. Innovation models are a group of rules, regulations, procedures and practices rationalizing innovation processes (Barbieri and Alvares, 2016, pp. 116).

In the context of relatively low and diversified expenditures on $R \& D$, it would be justified for managers to focus on systemic behaviour consistent with the assumptions of the fourth generation of methods of managing R\&D activity. The essence of this concept is a rational coordination of structural and process aspects of this activity carried out within an economic entity with external organisations. In this way, a research network structure is created, supported by an IT system, which rationally uses human, organisational, technical and financial resources. As a result, flexible structures are created, consisting of research and development units functioning in the structures of various economic entities. These units, thanks to their intellectual resources, methodically solve emerging problems, exchange data, information and knowledge about the results of work, placing them in common databases. The structures created in this way are sometimes called virtual $R \& D$ structures. Work in such structures can be carried out according to two concepts based on (Baruk, 2009, pp. 62-67):

1) assigning tasks to be performed by particular partners sometimes located in different countries, in different geographical zones, according to the modular structure of the product, which means that a specific unit is responsible for the development of a specific module in all phases of its development,

2) assigning tasks to be performed by particular partners according to the R\&D cycle phase. As a consequence of this division of tasks, each 
organisation belonging to the network is responsible for the implementation of a different phase of the R\&D process (e.g. development of: a concept, a project, a prototype, conducting tests and studies, etc.).

In both cases, the efficiency of operation depends on maintaining interactive communication between participants of $R \& D$ processes, provided by IT systems.

It seems that the weakness of the hitherto applied $R \& D$ policies is their insufficient targeting with the knowledge of basic relations, such as:

1) product - technology,

2) product - market,

and the resulting $R \& D$ strategies. A special role should be assigned to offensive strategies, typical for high market attractiveness and high competitive position of an economic entity.

Due to high costs of R\&D works, often exceeding financial possibilities of individual economic entities, it is justified to focus the R\&D policy on cooperation of many institutions with appropriate resources, especially human resources (mainly in the field of basic and applied research), which are lacking in many enterprises. It is also justified, to a greater extent than before, to support $R \& D$ activity with a rational $R \& D$ policy of the government covering: development of regulatory solutions, initiating R\&D and training programmes, shaping infrastructure conducive to $R \& D$ activity, $R \& D$ and innovation culture, financing or co-financing of $R \& D$ works, etc. 


\section{Bibliography}

1. Barbieri, J. C., Alvares, A. C. T. (2016). Sixth generation innovation model: description of a success model. Innovation \& Management Review, Vol. 13, No. 2, (116).

2. Baruk, J. (2009). Zarzqdzanie wiedza i innowacjami. Toruń: Wydawnictwo Adam Marszałek w Toruniu.

3. Baruk, J. (2018). Wybrane aspekty innowacyjności przedsiębiorstw funkcjonujących w UE. Kwartalnik Nauk o Przedsiębiorstwie, No. 1, (88).

4. Baruk, J. (2016). Miejsce działalności badawczo-rozwojowej w polityce rozwojowej przedsiębiorstw. Marketing Instytucji Naukowych i Badawczych, 20(2), (61).

5. Bogers, M. (2011). The open innovation paradox: knowledge sharing and protection in R\&D collaborations. European Journal of Innovation Management, Vol. 14, No. 1, (94).

6. Chen, X., Xia, Y., Yang, J. (2018). Analysis on the Impact of Government-Enterprise Cooperation on Technological Innovation and its Economic Consequences. Business and Management Studies, Vol. 4, No. 4, (39).

7. Deloitte (2016). Badania i rozwój w przedsiębiorstwach 2016. Deloitte. (10).

8. Gloet, M., Samson, D. (2019). Knowledge and Innovation Management: Creating Value. Effective Knowledge Management Systems in Modern Society. IGI Global. Chapter 2(20).

9. Griffin, R. W. (2007). Podstawy zarzadzania organizacjami. Warszawa: Wydawnictwo Naukowe PWE.

10. GUS (2019). Nauka i Technika w 2017 r. Warszawa, Szczecin: Główny Urząd Statystyczny.

11. Li, W., Zhang, Y., Wei, Y. (2018). Management Capabilities and Corporate Environmental Performance: The Moderating Role of Top Management Team Faultlines. Science Journal of Business and Management, Vol. 6 No. 1, (22).

12. OECD (2015). Podręcznik Frascati 2015. Zalecenia dotyczqce pozyskiwania i prezentowania danych z zakresu działalności badawczej i rozwojowej. Warszawa: GUS.

13. OECD (2015). Frascati Manual 2015: Guidelines for Collecting and Reporting Data on Research and Experimental Development. OECD. 2018 Statistics Poland for this Polish editio.

14. Salisu, Y., Abu Bakar, L. J. (2019). Technological Capability, Innovativeness and the Performance of Manufacturing Small and Medium Enterprises (SMEs) in Developing Economies of Africa. Journal of Business and Management, Vol. 21, No. 1, (58).

15. Strategia „Europa 2020” (2015). Ministerstwo Gospodarki. Warszawa http://www.mg. gov.pl/Bezpieczeństwo+gospodarcze/Strategia+Europa+2020 (accessed on 09.10.2015).

16. Wang, T., Chen, M. (2017). Perceiving Organisational Culture Influence on Knowledge Management Performance. Science Journal of Business and Management, Vol. 5 No. 3, (96).

17. Xie, Z., Hall, J., McCarthy, I. P., Skitmore, M., Shen L. (2016). Standardization efforts: The relationship between knowledge dimensions, search processes and innovation outcomes. Technovation, Vol. 48-49.

18. https://ec.eurostat/tgm/printTable. (accessed on 31.12.2018 r.). 
Jerzy Baruk, Ph.D. Eng., Maria Curie-Skłodowska University in Lublin, Poland - a retired academic of the Institute of Marketing and Management of the Faculty of Economics at the Maria CurieSkłodowska University in Lublin. His research work focuses on the organisational and economic aspects of innovation activities, innovation management and management through innovation, as well as the impact of innovation on the efficient functioning of organisations. Knowledge management and the relationship between the management of knowledge and innovation creation constitutes another area of his research work. Author of over 350 scientific publications on the broader aspects of innovation and knowledge management published in domestic and international scientific journals and conference materials. Author of four books and numerous other co-authored publications. He has also presented the results of his scholarly work and research at many domestic and international conferences. A fellow of the following learned organisations: Scientific Society of Organization and Management; Polish Association for Production Management; "Taures" Economic Initiative Enterprise in Warsaw; Lublin Scientific Society; Polish Praxeological Society; University - Industry - Science Partnership; Polish UNISPAR Working Group Society; Innovative Entrepreneurs' Club at the Lublin Development Foundation. Advisor in the Lublin Branch of the Scientific Society for Organization and Management as well as the "Taures" Economic Initiative Enterprise in Warsaw. 